\title{
The Application of Automated Testing and Research on the Quality of Student Life among Large Scientific and Educational Centers of Siberia
}

\author{
P.A. Kuznetsov \\ Department of Behavioral Medicine and Management \\ Siberian State Medical University \\ Tomsk, Russia \\ savlkuts3@gmail.com
}

\author{
N.S. Hoch \\ Department of Behavioral Medicine and Management \\ Siberian State Medical University \\ Tomsk, Russia \\ nhoch@yandex.ru
}

\begin{abstract}
This article analyzes the problems and advantages of using computer-based evaluations ofsociocultural conditions in relation to quality of life research among a diverse range of studentsin scientific and educational centers. The results of our research on the quality of life among students of scientific and educational centers in Tomsk, Russia are demonstrated by the use of the automated Russian versions of the World Health Organization Quality of Life-100 (WHOQOL-100) questionnaire. Specific trends based on gender were revealed in the quality of life selfassessments of students who had come from cities other than Tomsk. These trends were found in answers relating to following domains: Environment, Physical, Level of Independence and Spirituality/Religion/ Personal Beliefs. Additionally, suggestions for the improvement of quality of life among students in scientific and educational centers are presented.
\end{abstract}

Keywords - quality of life, WHOQOL-100, computer technologies, automated psychodiagnostics, students.

\section{INTRODUCTION}

In modern socio-economic conditions, the system of higher education is viewed by young people as not only a factor of personal and professional development, but also as a mechanism for social advancement which allows for better opportunities for the most talented of students to reach the highest levels of the societal hierarchy.Siberian scientific and educational centers, and in particular for leading Tomsk universities are characterized by their large number of out-ofstate and foreign students, which include students from all parts of the Russian Federation and students from PostSoviet regions, as well as students from overseas. For these groups of students, in addition to the need to adapt to the new conditions of higher education environment, severe problems arise in overcoming situations of socio-cultural deprivation and adjusting to the new lifestyle, including the building of a comfortable life, organization of a healthy lifestyle, and satisfaction of cultural needs and interactions[1,2]. However, the problem of analyzing socio-cultural environmental conditionsof scientific and educational centers in accordance with the needs of students of different categories remains one of the least researched issues of this field. One of the ways to solve this problem is the use self-assessments of quality of life by participants of the educational process.

The application of the traditional method of face-to-face testing for these aims is problematic, due to the fact that the collection of materials and processing of data requires a great amount of time. The most efficient solution under the given conditions is the application of modern information technologies, in particular automated diagnostics systems, which helped to optimize the research results. In this case, the psychodiagnostics process was eased significantly for the respondent by a number of factors, including an easy to use questionnaire interface, the possibility for distance testing, the simplicity of filling out electronic forms, and the opportunity to get results and toform conclusions immediately.

Benefits for researchers, in comparison with traditional testing format, include a significant simplification of theinformed consent collecting procedure, the opportunity tomore rapidly form the research database, to streamline the process of mass data processing, and the opportunity to identify non-obvious information.

Since the 1980'sthe following two approaches in quality of life study have been developed: subjective and objective. Study of self-assessment in the field of psychology arerepresented by works of Russian authors including: A.B. Baranova, G.N. Golovina, B.I. Kulaykin, V.A. Nepomnyaschaya, E.U. Rubanova, T.N. Savchenko, E.A. Uglanovaet al. According to this approach, the actual definition of quality of life is reflectedin the subjective experiences of the individual, which are formed on the basis of his or her own life experience and level of cultural and emotional development.

In this approach, the quality of life is presented as the wellbeing through which individuals experience inner satisfaction of his or her condition of life [3-6]. The WHO 
defines quality of life as 'an individual's perception of their position in life in the context of the culture and value systems in which they live, and in relation to their goals, expectations, standards and concerns' [7].The medical field uses the concept ofhealth related quality of life. This means that quality of life is an integral characteristic of the patient's physical, mental, social, and emotional states, which are assessed on the basis of the patient's subjective perception. The assessment of quality of life takes into account that various life facets of the patient are both directly and indirectly dependent on health status. On the whole, diagnostic instruments allow us to evaluate self-assessments of the physical, mental, social, economic and spiritual aspects of a patient's life. It should be noted that for last 30 years many diagnostic tools were designed in an attempt to create optimum methodsto study a population's quality of life.

Among these methods, it can be noticedthat there are specialized surveys which were designatedto study certain nosology in various medical fields (e.g. Gastrointestinal Symptom Rating Scale, Functional Assessment of Multiple Sclerosis, Oral Health Quality of Life).Additionally, there are psychological surveys, which are designed to study subjective wellbeing and life satisfaction (e.g. Quality of Life Enjoyment and Satisfaction Questionnaire, Psychological General Well-Being Index, Diener, Emmons, Larsen, Griffin, 1985; Pavot, Diener, 1993).

As shown by structural analysis, the surveys described above are insufficiently informative as they do not contain enough indicators of general aspects of student life in studies of quality of life, which assess the functional quality of complicated social systems, such as those found in scientific and educational centers. The most optimal method is the application of general questionnaires, which relate to healthy and sickly respondents. The most popular diagnostic tools of this group consist of the following: World Health Organization Quality of Life-100 (WHOQOL-100) questionnaire, Medical Outcomes Study-Short Form-36 (MOS SF-36), European Quality of Life Questionnaire (EQ5D).

Relative analysis of these popular questionnaires and also results of comparative empirical studies, which were conducted with participation of patients with different chronic diseases [8-9], show that WHOQOL-100 is the most informative for our research. This questionnaire contains detailed descriptions of various domains and facets also have distinctive and important indicators which allow us to assess two domains: Environment and Spirituality/Religion/ Personal Beliefs, which are absent,from other questionnaires.

The domain "Environment" consists of the following facets: financial resources, freedom, physical safety and security, health and social care(accessibility and quality), home environment, opportunities for acquiring new information and skills, participation in and opportunities for recreation/leisure,

physical

environment (pollution/noise/traffic/climate), andtransport. Also as a part of the questionnaire is the especially important domain of "Spirituality/Religion/Personal beliefs", which opens the door for more diagnostic opportunities. These two sections of the WHOQOL-100 questionnaire allow us to reach the goals of this study, as long as they reflect infrastructure operation of accommodation and also identify personal beliefs and how they affect at quality of life in diverse religious and cultural environment.

It should be emphasized that the authors of WHOQOL100 consider the quality of life as a multidimensional structure which includes the individual's perception of his or her physical and psychological condition, level of independence, relationships with another people and personal beliefs, and also attitude to significant environmental characteristics [108]. The WHOQOL-100 offers an opportunity for direct evaluation of the respondent's perception of his or her quality of life and health in general. It can be applied toa widerange of contingents, in order to as cover the full spectrum of functions, disabilities, and distresses which are related to quality of life.

The WHOQOL-100 is available in 20 languages, whichallows for cross-cultural studies in multi-ethnic environment, particularly in large scientific and educational centers, in which respondents come from different countries and speak different languages.

\section{METHODS}

Our study uses the automated Russian version of the WHOQOL-100 questionnaire for all data collection. Russian version wasdeveloped in St. Petersburgat the V.M. BekhterevPsychoneurological Research Institute, which is recognized as a WHO collaborating center. The interview process of respondents and also data collection was conductedby the application of the automated multimodal system of psychodiagnostics methods (AMSPM), which was designed and approved by stuff of Department of Behavioral Medicine and Management at Siberian State Medical University [11].

Four groups of freshmen and sophomore students participated in the research from the leading universities of Tomsk: Siberian State Medical University (SSMU), National Research Tomsk Polytechnic University (NR TPU), and the National Research Tomsk State University (NRTSU). Groups 1 and 2 included men and woman who live in Tomsk on a long term basis. Groups 3 and 4 included non-resident men and woman who came from Tomsk Oblast, Kemerovo Oblast, Krasnoyarsk Krai, Tuva Republic, Republic of Khakassia, and Altai Republic. All non-resident students were living in a dormitory. The total number of respondents was 310 people(Fig. 1). As an inclusion criterion in the selection process, asatisfactory academic performance was 
used as an indicator of the students' interest in the learning process.

FIGURE 1.THE NUMBER OF RESPONDENTS IN THE STUDY GROUPS

\begin{tabular}{|c|c|c|c|}
\hline \multicolumn{2}{|c|}{ Tomsk residents } & \multicolumn{2}{c|}{ Non-Tomskresidents } \\
\hline Male & Female & Male & Female \\
\hline 59 & 70 & 87 & 94 \\
\hline
\end{tabular}

\section{RESULTS}

As shown in the analysis of the initialresults of the study, the assessment of quality of life in six broad domains (Physical Health, Psychological, Level of Independence, Social Relations, Environment, Spirituality/Religion/Personal beliefs) for the vast majority of participants were in the range of $12-20$ points. This corresponds to the following levels of quality of life: medium, good, very good, and also indicates at least a satisfactory relation of conditions among scientific and educational centers of Tomsk city to needs of members of different ethnic and regional groups. A more detailed analysis of the results revealed the following: self-assessment of quality of life in "Psychological" and "Social Relationships" domains were in the range of 13 - 17 points. This indicates a lack of standing systematic disabilities of participants, which could inhibit positive attitudes, active professional developments, new social relationships, and obtaining necessary social support. This conclusion is also demonstrated by the data obtained from the group of participants that answered with a "good" overall quality of life and level of independence (Fig. 2).

FIGURE 2.COMPARISON OF ASSESMENTS OF STUDENTQUALITY OF LIFE

\begin{tabular}{|c|c|c|c|c|}
\hline \multirow{3}{*}{ WHOQOL-100domains } & \multicolumn{4}{|c|}{ Student groups } \\
\hline & Male Tomsk residents & Female Tomsk residents & Malenon-Tomskresidents & Femalenon-Tomsk residents \\
\hline & 1 & 2 & 3 & 4 \\
\hline Physical & $15.92 \pm 0.31$ & $15.17 \pm 0.43$ & $16.63 \pm 0.43$ & $14.63 \pm 0.35^{* *}$ \\
\hline Psychological & $16.09 \pm 0.23$ & $15.69 \pm 0.45$ & $15.40 \pm 0.45$ & $15.60 \pm 0.37$ \\
\hline LevelofIndependence & $19.05 \pm 0.35$ & $19.46 \pm 0.25$ & $19.25 \pm 0.35$ & $18.00 \pm 0.49 * *$ \\
\hline SocialRelationships & $16.73 \pm 0.21$ & $16.96 \pm 0.19$ & $16.26 \pm 0.39$ & $16.39 \pm 0.44$ \\
\hline Environment & $15.98 \pm 0.23 *$ & $15.67 \pm 0.25 *$ & $14.52 \pm 0.74$ & $13.35 \pm 1.11$ \\
\hline $\begin{array}{l}\text { Spirituality/Religion/ } \\
\text { PersonalBeliefs }\end{array}$ & $17.79 \pm 0.27^{*}$ & $17.45 \pm 0.49^{*}$ & $16.35 \pm 0.42$ & $16.30 \pm 0.54$ \\
\hline Overall quality of life & $16.98 \pm 0.29$ & $16.82 \pm 0.34$ & $16.40 \pm 0.54$ & $15.67 \pm 0.88 * *$ \\
\hline
\end{tabular}

At the same time, participants evaluated their quality of life differently in some life aspects. As follows, non-resident students (groups 3,4) assessed life comfort in domains "Environment" and "Spirituality/Religion/ Personal Beliefs" significantly lower.This indicates limitations on the meetingof spiritual needs and implies deficits inprevious experience in relation to understanding and overcoming difficulties of student life.

It is fitting to mention that the problemsconcerning the psychophysiological aspects of adaptation of students to environmental factors specific for the large scientific and educational centers in Russia has long been the focus of human ecology, physiology, and pedagogical research. These studies show that new socio-cultural and educational conditions of university lifecause the activation of adaptation processes, and afterthe exhaustion of the body's natural reserves, this causes an unfavorable course of adaptation processes, especially during first year of study [12-13].The results of our study also show that there is significant strainon physiological resources adaptation of non-resident

\footnotetext{
* Statistically significant differences between groups $3,4(\mathrm{p} \leq 0.05)$

$* *$ Statistically significant differencesbetween groups $1,2,3(\mathrm{p} \leq 0.05)$
}

first year students, leading to as low-level of self-assessment of wellbeing in the domain of "Environment" related first of all with to the violation of feeling physical safety and protection, in addition to low-level of recreational opportunities.

On the other hand, psychological comfort in a living environment consists not only of components directly related to education and interpersonal relationships in the educational setting. In recent cultural studies of Siberian nations, it was found that a very important condition of subjective wellbeing for many modern people is the correspondence of socio-cultural conditions to personal beliefs, spiritual and especially religious needs [14]. Results of our study show that in the first phases of cultural adaptation one of the most significant difficulties in spiritual life for non-residence students is the limitation of opportunities of satisfaction for ethnically specific spiritual and religious needs. It is connected with the fact that many students are from the autonomous territories of Siberia with 
different religious traditions (Christianity, Buddhism, Shamanism, Islam, etc.).

In this study specific trends based on gender were revealed in the quality of life self-assessments of nonresident students. In the group of female, non-Tomsk residents (group 4) the assessments in domains of "Physical" and "Level of Independence" were significantly lower than in other groups.

In the process of additional individual and group interviews,female, non-resident students were confirmed to have lower evaluations of quality of physical functioning, including health, levels of life activities, energy, and also quality of sleepthan other groups. Very often were noted the deterioration in the ability to perform daily activities, uncomfortable living environments in a dormitory, and lack of access and quality of healthcare.

It is important to note that quality of physical functioning in the conditions of higher educationwere assessed to be at a lowlevel by first and last-year students at universities in the European and Asian parts of Russia in studies which were provided with an application of the MOS SF-36 in the following sections: "physical functioning", "bodily pain", "general health perceptions" and "vitality" [15 $-17]$.

The results which were revealed in our research and in studies of other authors show that the lacking at the local level of self-assessments of quality of physical functioning and sometimes overall quality of life in university conditions among the female, non-Tomsk residents group indicates that the existence of systemic gender-associated problems in the provision of comfortable socio-cultural conditions in higher educational systems and, undoubtedly, demand further exploration.

\section{CONCLUSION}

In summary, it is possible to conclude that application of automated testing methods using the WHOQOL-100 have significant operational advantages in analysis of the quality of conditions of student life among large scientific and educational centers. Application of the WHOQOL-100 questionnaire allows the analysis of subjective assessments of student quality of life to evaluate problematicaspects, include specific trends based on gender, infrastructure, social, and cultural environment of large scientific and educational centers in Tomsk, which reduce the effectiveness of training students from other cities. The outcomes of our research allow us to outline the direction of improving conditions of living, education, andleisure according to goal of increasing the quality of life and forming a positive image of Tomsk city as a scientific and educational center with a high level of life to increase the attractiveness of Tomsk universities for non-resident and foreign students.

\section{REFERENCES}

[1] L.A.Proskuryakova, "The problem of modern society - improving the quality of life of students"(in Russian), Almanac of Modern Science and Education., vol. 5, pp. 174-176, 2007

[2] N.S. Hoch. (2013) Psychological hardiness as a resource adaptation of students from Tuva to the educational environment of the scientific centers of Siberia [online]. Available: http://www.scienceeducation.ru/113-10953

[3] A.V. Baranova and V.A. Khashchenko, "Socio-psychological factors of assessment of quality of life," The 3rd All-Russian Congress of Psychologists, Saint Petersburg, Jun. 25-28,2003.

[4] V.I. Kulaikin, G.M.Zarakovsky, E.E. Zadesenets, "The concept of quality of life as a management tool of socio-economic development of Russia," Russia: Path to Social Government, Moscow, Jun. 6, 2008.

[5] A.A. Kulik (2012) Interrelation of Life Quality Parameters with Subjective Assessment of the Region [online]. Available: http://cyberleninka.ru/

[6] T.N. Savchenko and G.M. Golovina, Subjective quality of life: approaches, evaluation methods, applied research, Moscow, Russia: Institute of Psychology Russian Academy of Sciences, 2006, p. 170.

[7] A. Bowling,MeasuringDisease: A ReviewofDiseasespecificQualityofLifeMeasurementScale,Buckingham, OpenUniversityPress, 2001.

[8] D.Unalan et al."Comparison of SF-36 and WHOQOL-100 life quality scales in early period tuberculosis subjects," JPMA. The Journal of the Pakistan Medical Association., vol. 11, pp. 1161-1167, 2012.

[9] D. Unalan et al. "Comparison of SF-36 and WHOQOL-100 in patients with stroke,"Neurology India., vol. 4, p. 426, 2008.

[10] Assessment of quality of life schizophrenia patients during supportive therapy. Guidelines.The V.M. BekhterevPsychoneurological Research Institute, St. Petersburg, Russia, 2011, p. 22.

[11] P.A. Kuznetsov and N.S. Hoch "Application of computer technologies in assessment of quality of life," IT in science,management, social sphere and medicine, Tomsk. Russia, 2015.

[12] N.A. Aghajanianet al., "The problem of student health and the prospect of development,"All-Russian Conference Lifestyle and Student Health, Moscow, Russia, 1995.

[13] G.A. Zelezinskaya et al., "Quality of life of medical students and clinical residents," Medical journal, vol. 18, pp.53-55, 2006.

[14] T.P.Minchenko, "The sociocultural adaptation of the population of Siberia in the age of globalization and postsecularity: regional specificity (on example of cultural values of the peoples of the Tomsk region)," Tomsk State University Journal of Cultural Studies and Art History, vol. 4, pp. 35-43, 2011.

[15] E.G. Blinova, "Quality of life and lifestyle of students," Ural Medical Journal, vol. 6, pp. 73-75, 2008.

[16] L.V. Byankina et al., "Self-esteem of the health by the professional education institutions students of Khabarovsk as a component of their psychophysical condition," Scientific theory journal "Uchenyezapiskiuniversitetaimeni P.F. Lesgafta" vol. 110, pp. 24-28, 2014.

[17] T.A. Naidanovaet al., "Quality of life of students of Ural State Medical Academy in the context of their gender identity," All-Russian science conference Strategies ofinnovation development of medical university, Ekaterinburg, Russia, May 15-16, 2013. 